\title{
Solid organ transplantation and HIV: A changing paradigm
}

\author{
BL Johnston $M D^{1}$, JM Conly $M^{2}$
}

$\mathrm{T}$ he history of HIV and solid organ transplantation dates to the original discovery of the virus itself. It includes a history that informed the early belief that HIV infection should represent a contraindication, relative if not absolute, to organ transplantation (1-3). However, with the introduction of highly active antiretroviral therapy (HAART) more than 10 years previously, there has been a dramatic improvement in survival rates in those infected with HIV. Using data from a multinational collaboration of HIV cohort studies (4) in Europe and North America, investigators estimated that the average number of years remaining to be lived for a 20-year-old who was newly starting antiretroviral therapy was approximately twothirds that of the general population. At the same time, epidemiological studies (5-7) in HIV-infected persons reported an increasing number of individuals experiencing diseases other than HIV-related infections, in particular an increasing prevalence of chronic liver and renal disease. It has become readily apparent that there will continue to be a need for managing end-stage organ failure in HIV-infected patients. Over the past decade, and especially the past five years, there has been a number of published papers reporting the outcomes of HIV-infected patients who have undergone solid organ transplantation. Given this background, it was considered timely to provide an update of the evolution of solid organ transplantation in HIVinfected patients, and discuss whether it is ready to be considered a standard of care in 2008.

As early as the mid-1980s, it was apparent that HIV could be transmitted in the setting of solid organ transplantation through donor organs (living and cadaveric) as well as through blood transfusions (1). A spectrum of disease was noted, ranging from asymptomatic infection to AIDS, but the general sense was that the incubation period for advanced disease was shortened in those with HIV who underwent solid organ transplantation (1). The reasons remained to be elucidated, but were often attributed to the combined immune suppression of the antirejection drugs and the HIV infection itself. Several publications from the pre-HAART era supported the notion that HIV patients who underwent solid organ transplantation did more poorly than their non-HIV-infected counterparts. Erice et al (8), in a case series and review of the literature, found that 25 of $88(28 \%)$ patients developed AIDS (mean of 27.5 months posttransplantation), with $80 \%$ AIDS-related mortality (on average, 37 months post-transplantation). The Pittsburgh transplant group in the United States (US) reported that five of 15 (33\%) adult HIV-infected organ transplant recipients died of AIDS, although the post-transplantation mortality in pediatric HIV patients was only 10\% (9). In France, Bouscarat et al (10) documented a seven-year survival rate of $36 \%$ among their $11 \mathrm{HIV}$ infected orthotopic liver transplant patients, compared with approximately $70 \%$ among non-HIV-infected liver transplant recipients during the same time period. The experience in the United Kingdom (UK) was similar. Twenty-six hemophiliac men underwent liver transplantation between 1982 and 1996, six $(23 \%)$ of whom were HIV infected (11). The majority of these patients (69\%) had hepatitis C virus (HCV)-associated cirrhosis. The one- and three-year survival rates for the HIVinfected patients were $67 \%$ and $23 \%$, compared with $90 \%$ and $83 \%$ in the non-HIV-infected patients $(\mathrm{P}=0.0003)$. In South Africa, 18 patients who acquired HIV after transplantation were followed over several years (12). The cumulative one- and five-year survival rates were $50 \%$ and $44 \%$, with the mean duration from the time of diagnosis of HIV to death being approximately six months. Finally, data from the US Renal Data System (13) $(63,210$ cadaveric solitary renal transplant recipients with HIV serology results) provided the outcomes for 32 HIV-infected patients who underwent renal transplantation between January 1, 1987, and June 30, 1997 (13). The HIV patients were younger, had younger donors and better human leukocyte antigen matching than the non-HIV-infected patients in the cohort. Patient and graft five-year survival rates were significantly $(\mathrm{P}<0.05)$ reduced in the HIV group $(71 \%$ and $44 \%$, respectively) than in the entire cohort $(78 \%$ and $61 \%$, respectively), despite factors that normally predict better outcomes.

Given this evidence, the results from a 1997 survey (2) of 248 US renal transplant centre directors, who were asked about their approach to HIV-infected patients with end-stage renal disease, can hardly be surprising. Among the 148 respondents (who performed 65\% of renal transplants in 1996), 84\% would not transplant an individual who refused HIV testing, $88 \%$ would not transplant a cadaveric kidney into an asymptomatic HIV-infected patient with end-stage renal disease who was an otherwise good candidate for transplantation, and 91\% would not transplant a living donor kidney into an asymptomatic HIV-infected individual. The authors of the study commented that a 1989 survey of British and Irish nephrologists gave similar results, with $73 \%$ reporting that they would exclude HIVinfected patients from transplantation.

However, if one looks beyond the negative results of the early solid organ transplantation experience among HIV-infected

\footnotetext{
${ }^{1}$ Queen Elizabeth II Health Sciences Centre and Dalhousie University, Halifax, Nova Scotia; ${ }^{2}$ Departments of Medicine, Pathology and Laboratory

Medicine, and Microbiology and Infectious Diseases, University of Calgary, Calgary, Alberta

Correspondence and reprints: Dr BL Johnston, Queen Elizabeth II Health Sciences Centre, 5014ACC - 1278 Tower Road, Halifax,

Nova Scotia B3H 2Y9. Telephone 902-473-5553, fax 902-473-7394, e-mail ljohnsto@dal.ca

Received and accepted for publication November 5, 2008
} 
patients, it is noteworthy that some of the patients did quite well. While the five-year survival rate was approximately $40 \%$, there were a number of survivors. As early as 1996, it was observed that patients with HIV could expect increased survival with the large array of antiretroviral therapies that were becoming available, and perhaps they could merit consideration for transplantation (14). In his discussion of the findings from the survey of the renal transplant program directors, Spital (2) emphasized that until that time, patients in the reports were not treated with modern antiretroviral drugs. He also reflected that laboratory tools, such as plasma viral load measurement and CD4 lymphocyte counts, were more widely available and should make the identification of HIV-infected patients who would be better transplant candidates possible.

It was early in the present decade that the first case series of HIV-infected individuals who underwent solid organ transplantation in the HAART era began appearing. In San Francisco (USA), Stock et al (15) reported on nine HIV patients who received transplants in 2000 (two living donor kidneys, four cadaveric kidneys, two living donor livers and one cadaveric liver). All six kidney transplant recipients were alive between four and 70 weeks post-transplant, although biopsy-proven rejection occurred in four of six recipients. One patient receiving thymoglobulin for rejection developed Staphylococcus aureus endocarditis. Of the three liver recipients, two were alive with undetectable hepatitis B viral load and one died of progressive liver insufficiency from HCV. HIV viral load remained undetected in all patients who stayed on their HAART, and there was no progression in their HIV. Although there were no AIDS-related opportunistic complications, there were several other infectious complications. Significant effects on the patients' cyclosporine levels were also noted. This small cohort of HIV solid organ transplant patients would provide early insights into the risks and benefits of organ transplantation, and would highlight some important medical issues. Investigators in the US (Pittsburgh and Miami) found that 14 of 16 patients remained alive after liver transplantation (13 of them for more than 12 months post-transplantation), and tacrolimus toxicity occurred in six patients due to pharmacological interactions with protease inhibitors (16). Similar observations were made from a small cohort of HIV-infected patients who underwent liver transplantation in Germany (17). Six of seven patients (four with HCV and three with hepatitis B virus [HBV]) were alive at a median of 14 months, and there was only one episode of acute rejection. Recurrent HCV occurred in all four HCV-infected patients, but none of the HBV-infected patients had recurrence. In France, seven HCV-HIV coinfected patients were transplanted between December 1999 and December 2002, for end-stage liver disease due to HCV (18). All seven were on HAART, with an undetectable viral load and median pretransplantation CD4 count of 306 cells $/ \mathrm{mm}^{3}$. There were two deaths, and four patients were found on liver biopsy to have mitochondrial toxicity, reflecting that liver transplantation in the setting of HCV-HIV coinfection is characterized by problems not seen with HBV-HIV coinfection. In the UK, Norris et al (19) published their experience with 14 HIVinfected liver allograft recipients who were transplanted between 1995 and April 2003 (19). All but one received HAART after transplantation. At follow-up (668 to 2661 days), all seven non$\mathrm{HCV}$ infected patients were alive with normal graft function (and no HBV recurrence), but five of seven $\mathrm{HCV}$-infected patients were dead (four of complications from recurrent $\mathrm{HCV}$ and sepsis). A 2004 analysis (20) of data from the US Renal Data System $(27,851$ patients transplanted between January 1, 2006, and May 31, 2001; 47 [0.2\%] of whom were HIVinfected) found that graft and patient survival rates were similar in HIV-infected and noninfected kidney recipients.

Medical advances reopened the debate on whether HIVinfected patients were suitable solid organ transplant candidates. However, it was equally apparent that there were important questions that needed to be answered around transplantation in the setting of HIV infection. Some of these issues were related to the toxicity and interactions of immunosuppressive and antiviral drugs (short- and longterm); the impact of coinfection with HCV, HBV and other viruses; the effect of HIV on rejection; and the long-term effect of transplant- and HIV-associated immune suppression on malignancy rates $(21-23)$. It is also well recognized that there is a large disparity between demand (the number of individuals requiring a transplant) and supply (the number of organs available) $(22,24)$. While there may be several strategies to manage this disparity, one is to choose individuals for transplantation who will benefit the most from the donated organ, in terms of patient and graft survival rates (24). However, medical urgency is another important criterion in heart, lung and liver transplantation (25). We know from the literature that there are non-HIV status predictors for poorer patient and graft survival rates, such as age, race and certain underlying comorbidities that do not routinely exclude patients from consideration for organ transplantation. Halpern et al (25), in a 2002 sounding board article, made the case for offering transplantation to HIV-infected patients, noting that proof of relative efficacy has never been required for the initiation of new surgical procedures or the expansion of indications for established procedures.

While Halpern et al (25) did not believe that organ transplantation should be offered to HIV patients only in the context of well-controlled studies, they did acknowledge that some documentation of relative efficacy would be needed to gain the acceptance of physicians and the public, and that the best way to achieve this would be by performing these transplants at major centres where infectious diseases specialists can work closely with the transplantation teams and publish their results. Others (26) argued that transplantation in the setting of HIV infection would best be undertaken within the framework of safety and efficacy studies. To that end, researchers in the US at the Universities of Pittsburgh, Miami, Minnesota and California at San Francisco (UCSF), and King's College (London, UK) (27) and at UCSF (28) initiated research protocols to examine the outcomes of transplantation at their centres. The multicentre study by Ragni et al (27) reported that the cumulative survival rates among HIV-infected liver transplant recipients $(72.8 \%$ at 24 and 36 months) and HIVnegative recipients ( $81.6 \%$ and $77.9 \%$ at 24 and 36 months) were similar. Predictors of poorer survival rates in univariate analysis were HCV infection ( $\mathrm{P}=0.023)$, post-transplant antiretroviral intolerance $(\mathrm{P}=0.044)$, a post-transplant $\mathrm{CD} 4$ count less than 200 cells $/ \mathrm{mm}^{3}(\mathrm{P}=0.005)$ and post-transplant HIV viral load greater than 400 copies/mL. At UCSF, all 10 patients who received kidney transplants survived (mean follow-up of 
380 days) with functioning grafts, although 50\% experienced rejection (28). HIV viral load remained undetectable as long as HAART was maintained. Although CD4 counts dropped immediately after transplantation in most patients, they rebounded within several weeks, albeit dropping to less than 200 cells $/ \mathrm{mm}^{3}$ in patients treated for rejection with thymoglobulin. Data such as these prompted Fishman (29) to surmise in a 2003 editorial that transplantation for patients with HIV was no longer experimental, albeit not yet routine. However, he did note that full benefit relied on tolerance of HAART and that transplantation in HCV patients remained problematic, especially for liver transplant patients.

Whether from prospective clinical trials or retrospective reviews, several groups have reported their experience with solid organ transplantation, almost exclusively liver and kidney transplants, in HIV-infected patients over the past two years. In Spain, Castells et al (30) compared outcomes in nine HIV$\mathrm{HCV}$ coinfected patients and $18 \mathrm{HCV}$-infected patients who underwent liver transplantation between October 2002 and July 2005. Although the small numbers make it difficult to detect differences, three-year patient survival rates $(87.5 \%$ in coinfected patients and $93.7 \%$ in $\mathrm{HCV}$-monoinfected patients) and acute cellular rejection rates ( $44 \%$ versus $22 \%$ ) were similar in the two groups, although acute HCV occurred earlier and was more of a cholestatic nature in HIV-infected patient. In a retrospective case-control study (31) of $15 \mathrm{HIV}$-infected and 857 noninfected patients who had liver transplants at the University of Miami between June 1, 1999, and May 1, 2006, the overall cumulative survival rate was not different $(\mathrm{P}=0.20)$ between the two groups, with the three-year survival rate being $73.3 \%$ in HIV-infected patients and $79.4 \%$ in noninfected patients (31). However, infectious mortality was different, with $26.7 \%$ of HIV-infected recipients dying from infection versus $8.2 \%$ of noninfected recipients $(\mathrm{P}=0.006)$, despite adequate control of their HIV infection. The authors were unable to identify a reason for the difference in infectious mortality. All patients were successfully able to continue their HAART in the post-transplant period. Examining data from the United Network for Organ Sharing registry in the US, Mindikoglu et al (32) found that the two-year survival probability was lower (70\%) among the $138 \mathrm{HIV}$-infected patients who received a liver transplant than the probability $(81 \%)$ in the $30,520 \mathrm{HIV}$ negative patients. However, this excess mortality was entirely among those who were coinfected with HCV or HBV. After controlling for age, coinfection and liver disease staging scores, an excess risk for death of 1.41 (95\% CI 0.90 to 2.22) in HIVinfected recipients approached, but did not reach statistical significance. There were insufficient numbers of HBV-HIV coinfected patients to identify an excess mortality risk from HBV. Again, HCV appeared to be the major copathogen contributing to poorer outcome in HIV-infected liver recipients. Finally, a multicentre US collaborative (33) reported outcomes for 11 liver and 18 kidney HIV-infected patients who received transplants between March 2000 and September 2003, and were followed for a median of 3.4 years. Their results were compared with data from the Organ Procurement and Transplantation Network (OPTN) database. One- and three-year liver recipient survival rates were $91 \%$ and $64 \%$, respectively, and somewhat lower than in the entire OPTN cohort. The three-year liver graft survival rate was $64 \%$, again lower than that for the entire
OPTN cohort, but similar to cohort members older than 65 years of age. Kidney recipients' three-year survival rate was $94 \%$ with kidney survival of $83 \%$, both similar to the OPTN cohort. By three years, $70 \%$ of kidney recipients had experienced a rejection episode. There were no HBV reinfections, but $66 \%$ of HCV patients had recurrence of infection.

Overall, new data have emerged regarding liver and kidney transplantation in HIV-infected individuals. There are significantly better outcomes for HIV-HBV coinfected patients than for those with HCV-HIV coinfection. Indeed, patient and graft survival rates appear similar in HBV-HIV coinfected and HIVnegative/HBV-positive liver transplant recipients (34). Provided that patients continue with their HBV treatment post-transplantation, there has been no HBV recurrence. The same cannot be said for HCV-HIV coinfection, where recurrence of $\mathrm{HCV}$ is the norm, and patient and graft survival rates are poorer than in monoinfected patients. Unfortunately, a complete delineation of predictors for recurrence and poor outcomes is not available, and it remains difficult to conclusively identify a subset of HCV-HIV coinfected patients that can be reliably predicted to do better. The data on outcomes with anti-HCV treatment post-transplantation in the HIVinfected recipient are somewhat limited. Castells et al (35) found that only one of five HIV-infected patients started on pegylated interferon-alpha $2 \mathrm{~b}$ and ribavirin after liver transplantation achieved a sustained virological response. On the other hand, investigators in Germany (36) reported a sustained virological response in all four HIV-HCV transplanted patients treated with pegylated interferon-alpha $2 \mathrm{a}$ and ribavirin. Graft and patient survival rates are similar in HIV-infected and nonHIV infected kidney transplant patients, although rejection episodes appear somewhat more frequently. Patients generally tolerate their HAART post-transplantation and when on HAART, HIV viral loads are usually undetectable. There does not appear to be a progression of HIV disease in the setting of HAART and use of opportunistic infection prophylaxis. CD4 counts often drop immediately after transplantation and then rise over several weeks, but may be adversely affected by thymoglobulin administration for rejection episodes. Carter et al (37) found that CD4 counts decreased from a mean of 475 cells $/ \mathrm{mm}^{3}$ to 9 cells $/ \mathrm{mm}^{3}$ in $11 \mathrm{HIV}$-infected transplant recipients who received thymoglobulin, with recovery time ranging from three weeks to two years despite effective HIV suppression, and an associated increased risk of serious infections requiring hospitalization. There is the potential for drugdrug interactions that require active monitoring and management. As an example, addition of lopinavir plus ritonavir to the tacrolimus regimen in seven transplant recipients required reducing the tacrolimus dose by $99 \%$ (38). In another study (39), a patient experienced moderate-to-severe acute rejection when he stopped taking his nelfinavir, without telling his physicians, and his tacrolimus level became undetectable.

The success to date seen with liver and kidney transplantation in HIV-infected patients has been, in large part, related to selecting appropriate patients. Although criteria may vary slightly from centre to centre, for the most part, they are consistent in their requirements that include undetectable viral load on HAART, or prediction that HIV will be suppressed after transplantation in patients who have been intolerant of, not on, or recently started on HAART; CD4 count greater 
than 100 cells $/ \mathrm{mm}^{3}$ or greater than 200 cells $/ \mathrm{mm}^{3}$ if there has been a previous opportunistic illness; and no active opportunistic infections $(40,41)$. Opportunistic infections that represent exclusion criteria are progressive multifocal leukoencephalopathy, chronic intestinal cryptosporidiosis, brain lymphoma and documented multiresistant fungal infection (39). Solid tumours treated with curative intent that have been in remission for five years are allowed, as are adequately treated basal and squamous cell skin cancers (39).

It has been estimated that there are approximately 10,000 HIV-infected patients in Europe and North America who would be candidates for liver transplantation, given estimates of HIV, HBV and HCV prevalence (41). A 2005 survey (3) of centres participating in the Canadian HIV Trials Network reported a nonquantified, but perceived appreciable burden of viral disease among HIV-infected patients. There are a number of causes of kidney disease in HIV-infected patients. The increased life expectancy of HIV-infected individuals with chronic kidney disease has resulted in an increasing number of HIV-positive individuals with end-stage liver disease (7). We can expect that the numbers of HIV-infected individuals with

\section{REFERENCES}

1. Rubin RH, Jenkins RL, Shaw BW, et al. The acquired immunodeficiency syndrome and transplantation. Transplantation 1987:44:1-4.

2. Spital A. Should all human immunodeficiency virus-infected patients with end-stage renal disease be excluded from transplantation? Transplantation 1998;65:1187-91.

3. Cooper CL, DeForest J, Gill J, Lalonde R; CTN Co-infection Core Group. Barriers preventing liver transplantation in Canadians with HIV infection - perceptions of HIV specialists. Can J Gastroenterol 2007;31:179-82.

4. The Antiretroviral Therapy Cohort Collaboration. Life expectancy of individuals on combination antiretroviral therapy in high-income countries: A collaborative analysis of 14 cohort studies. Lancet 2008;372:293-9.

5. Krentz HB, Kliewer G, Gill MJ. Changing mortality rates and causes of death for HIV-infected individuals living in Southern Alberta, Canada from 1984 to 2003. HIV Med 2005;6:99-106.

6. Bica I, McGovern B, Dhar R, et al. Increasing mortality due to endstage liver disease in patients with human immunodeficiency virus infection. Clin Infect Dis 2001:32:492-7.

7. De Silva TI, Post FA, Griffin MD, Dockrell DH. HIV-1 infection and the kidney: An evolving challenge in HIV medicine. Mayo Clin Proc 2007;82:1103-16.

8. Erice A, Rhame FS, Heussner RC, Dunn DL, Balfour HH Jr. Human immunodeficiency virus infection in patients with solidorgan transplants: Report of five cases and review. Rev Infect Dis 1991;13:537-47.

9. Tzakis AG, Cooper MH, Dummer JS, Ragni M, Ward JW, Starzl TE. Transplantation in HIV+ patients. Transplantation 1990;49:354-8.

10. Bouscarat F, Samuel D, Simon F, Debat P, Bismuth H, Saimot AG. An observational study of 11 French liver transplant recipients infected with human immunodeficiency virus type 1 . Clin Infect Dis 1994;19:854-9.

11. Gordon FH, Mistry PK, Sabin CA, Lee CA. Outcome of orthotopic liver transplantation in patients with haemophilia. Gut 1998;42:744-9.

12. Kahn D, van Rensburg M, Botha JF, et al. HIV infection following transplantation: The South African experience. Transplant Proc 2001;33:3649-50.

13. Swanson SJ, Kirk AD, Ko CW, Jones CA, Agodoa LY, Abbott KC. Impact of HIV seropositivity on graft and patient survival after cadaveric renal transplantation in the United States in the pre highly active antiretroviral therapy (HAART) era: An historical cohort analysis of the United States Renal Data System. Transplant Infect Dis 2002;4:144-7.

14. Lee CA. Hope for haemophilic patients with hepatitis. Gut 1996;39:887-8. end-stage organ failure will only increase as survival improves and they begin to live into old age. The literature supports that organ transplantation is a reasonable therapeutic option for many of these patients. Despite this, Canadian centres responding to the above noted survey perceived a number of barriers to liver transplantation in HIV patients with liver disease, including a limited organ supply, HCV reinfection and surgical team willingness (3). Acknowledging the biases inherent in such a survey, it is probably fair to say that in Canada, we are not meeting the needs of our HIV-infected patients with end-stage organ failure requiring transplantation. Investigators and editorialists have been consistent in their recommendation that transplantation in the setting of HIV infection be performed only where there is a carefully coordinated and dedicated team that includes transplant surgeons, transplant infectious diseases clinicians, experienced HIV clinicians, nephrologists, hepatologists and immunologists available for routine patient care $(1,23,25,29)$. It behooves us to engage our transplant colleagues more effectively in pursuing this treatment for those HIV-infected patients who are good transplant candidates.

15. Stock P, Roland M, Carlson L, et al. Solid organ transplantation in HIV-positive patients. Transplant Proc 2001;33:3646-8.

16. Neff GW, Bonham A, Tzakis AG, et al. Orthotopic liver transplantation in patients with human immunodeficiency virus and end-stage liver disease. Liver Transpl 2003;9:239-47.

17. Vogel M, Voigt E, Schäfer N, et al. Orthotopic liver transplantation in human immunodeficiency virus (HIV)-positive patients: Outcome of 7 patients from the Bonn cohort. Liver Transpl 2005;11:1515-21.

18. Duclos-Vallée JC, Vittecoq D, Teicher E, et al. Hepatitis C virus viral recurrence and liver mitochondrial damage after liver transplantation in HIV-HCV co-infected patients. J Hepatol 2005;42:341-9.

19. Norris S, Taylor C, Muiesan P, et al. Outcomes of liver transplantation in HIV-infected individuals: The impact of HCV and HBV infection. Liver Transpl 2004;10:1271-8.

20. Abbott KC, Swanson J, Agodoa LYC, Kimmel PL. Human immunodeficiency virus infection and kidney transplantation in the era of highly active antiretroviral therapy and modern immunosuppression. J Am Soc Nephrol 2004;15:1633-9.

21. Fishman JA, Rubin RH. Solid organ transplantation in HIVinfected individuals: Obstacles and opportunities. Transplant Proc 2001:33:1310-4.

22. Roland ME, Havlir DV. Responding to organ failure in HIVinfected patients. N Engl J Med 2003;348:2279-82.

23. Roland ME, Stock PG. Review of solid-organ transplantation in HIV-infected patients. Transplantation 2003;75:425-9.

24. Douglas DD. Should everyone have equal access to organ transplantation? An argument in favour. Arch Intern Med 2003;163:1883-6.

25. Halpern SD, Ubel PA, Caplan AL. Solid-organ transplantation in HIV-infected patients. N Engl J Med 2002;347:284-7.

26. Roland ME, Lo B, Braff J, Stock PG. Key clinical, ethical, and policy issues in the evaluation of the safety and effectiveness of solid organ transplantation in HIV-infected patients. Arch Intern Med 2003;163:1773-8.

27. Ragni MV, Belle SH, Im KA, Neff G, et al. Survival of human immunodeficiency virus-infected liver transplant recipients. J Infect Dis 2003;188:1412-20.

28. Stock PG, Roland ME, Carlson L, et al. Kidney and liver transplantation in human immunodeficiency virus-infected I patients: A pilot safety and efficacy study. Transplantation 2003;76:370-5.

29. Fishman JA. Transplantation for patients infected with human immunodeficiency virus: No longer experimental but not yet routine. J Infect Dis 2003;188:1405-11. 
30. Castells L, Escartin A, Bilbao I, et al. Liver transplantation in HIV-HCV coinfected patients: A case-control study. Transplantation 2007;83:354-8.

31. Schreibman I, Gaynor JJ, Jayaweera D, et al. Outcomes after orthotopic liver transplantation in $15 \mathrm{HIV}$-infected patients. Transplantation 2007;84:697-705.

32. Mindikoglu AL, Regev A, Magder LS. Impact of human immunodeficiency virus on survival after liver transplantation: Analysis of United Network for Organ Sharing Database. Transplantation 2008;85:359-68.

33. Roland ME, Barin B, Carlson L, et al. HIV-infected liver and kidney transplant recipients: 1 - and 3-year outcomes. Am J Transplant 2008;8:355-65.

34. Samuel D, Weber R, Stock P, Duclos-Vallée JC, Terrault N. Are HIV-infected patients candidates for liver transplantation? J Hepatol 2008;48:697-707.

35. Castells L, Estaban JI, Bilbao I, et al. Early antiviral treatment of hepatitis $C$ virus recurrence after liver transplantation in HIV-infected patients. Antivir Ther 2006;11:1061-70.
36. Wojcik K, Vogel M, Voigt E, et al. Antiviral therapy for hepatitis C virus recurrence after liver transplantation in HIV-infected patients: Outcome in the Bonn cohort. AIDS 2007;21:1363-5.

37. Carter JT, Melcher ML, Carlson LL, Roland ME, Stock PG. Thymoglobulin-associated $\mathrm{Cd} 4+\mathrm{T}$-cell depletion and infection risk in HIV-infected renal transplant recipients. Am J Transplant 2006;6:753-60.

38. Teicher E, Vincent I, Bonhomme-Faivre L, et al. Effect of highly active antiretroviral therapy on tacrolimus pharmacokinetics in hepatitis $\mathrm{C}$ virus and HIV co-infected liver transplant recipients in the ANRS HC-08 Study. Clin Pharmacokinet 2007;46:941-52.

39. Jain AKB, Venkataramanan R, Shapiro R, et al. The interaction between antiretroviral agents and tacrolimus in liver and kidney transplant patients. Liver Transpl 2002;8:841-5.

40. Roland ME, Stock PG. Liver transplantation in HIV-infected recipients. Semin Liver Dis 2006;26:273-84.

41. Miró JM, Agüero F, Laguno M, et al. Liver transplantation in HIV/hepatitis co-infection. J HIV Ther 2007;12:24-35. 


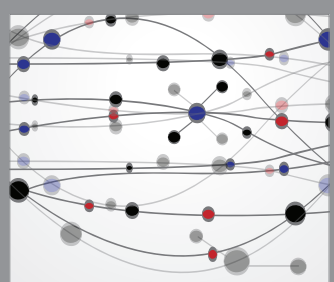

The Scientific World Journal
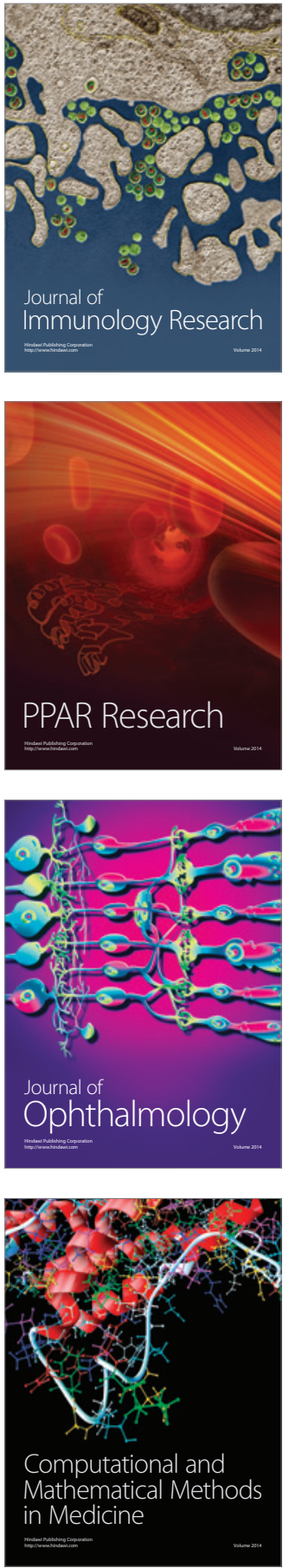

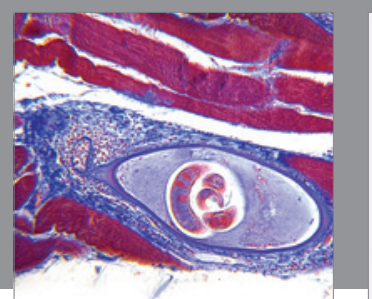

Gastroenterology Research and Practice

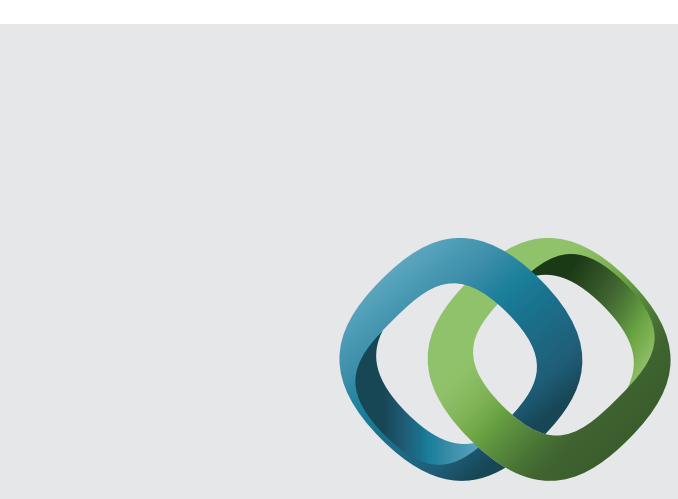

\section{Hindawi}

Submit your manuscripts at

http://www.hindawi.com
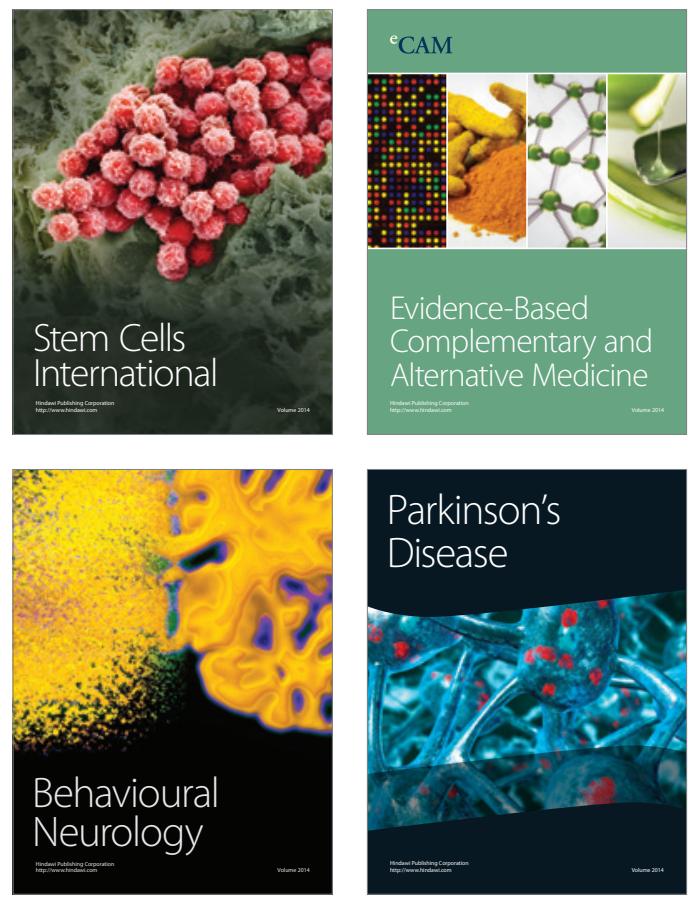
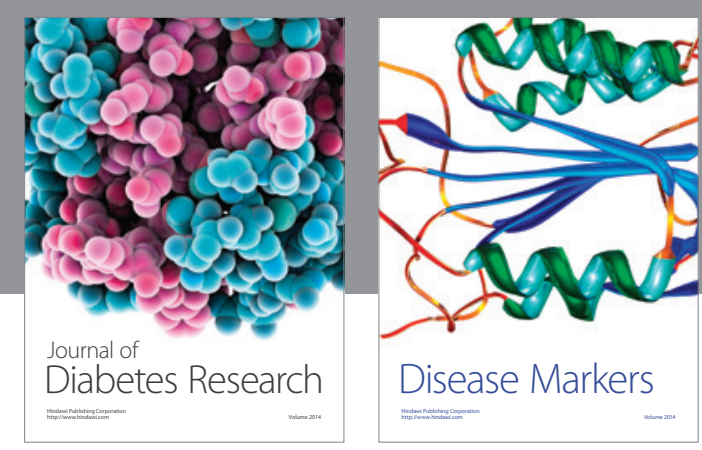

Disease Markers
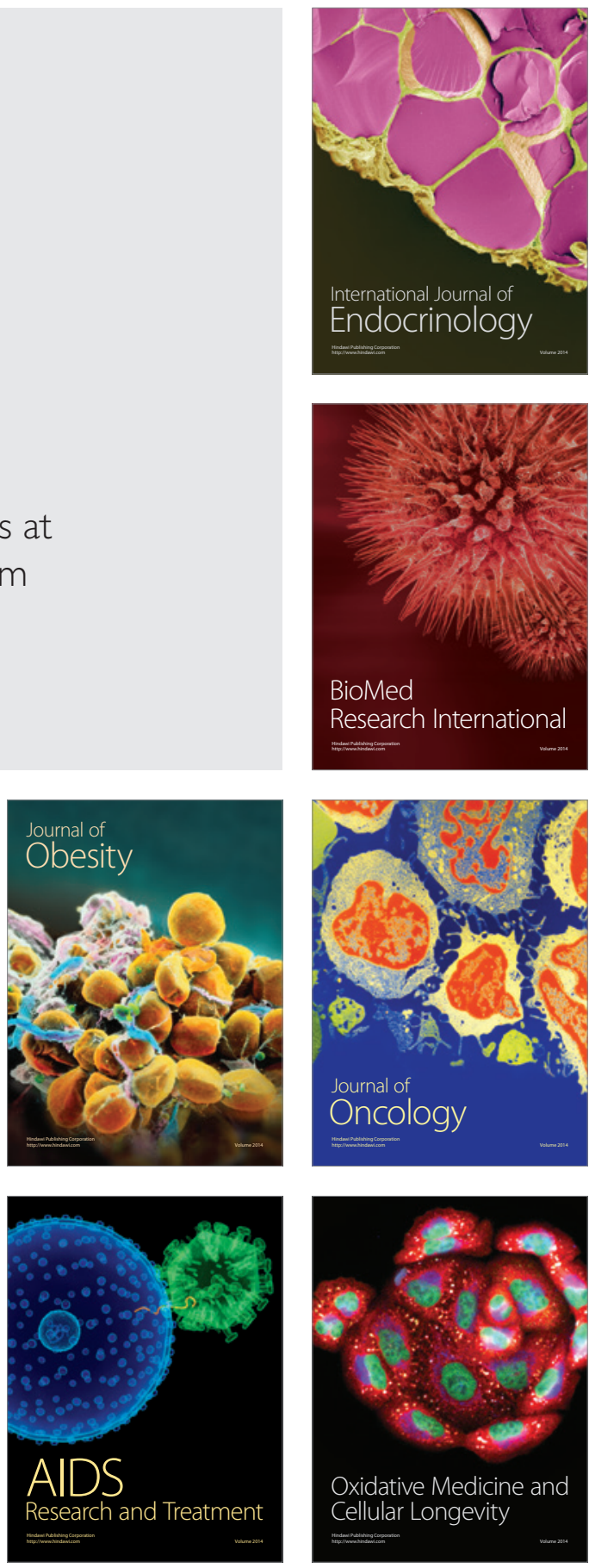